\title{
Greve dos servidores do Poder Judiciário
}

Conselho Nacional de Justiça

\begin{abstract}
PEDIDOS DE PROVIDÊNCIA No 0000091-03.2012.2.00.0000, 0000187-18.2012.2.00.0000, 0000264-27.2012.2.000.0000 e 0000270-34.2012.2.00.0000
\end{abstract}

RELATOR: CONSELHEIRO GILBERTO MARTINS

REQUERENTES: MARIA DO SOCORRO ABREU DE ARAÚJO ANTUNES, ALICE ROMANA DE JESUS PEREIRA, IDILBERTO NERY SILVA JUNIOR P MARIA DE BELÉM FERREIRA CAVALCANTE

REQUERIDO: TRIBUNAL REGIONAL DO TRABALHO - $8^{\mathrm{a}}$ REGIÃO ASSUNTO: $\quad$ TRT 8 ${ }^{\mathrm{a}}$ Região - Processo no ${ }^{\mathbf{0}}$ 1514/2011 - Servidor - Participação - Greve - Devolução - Descontos - Vencimentos - Oportunização - Direito - Compensação - Dias Paralisados.

\section{ACÓRDÃO}

SERVIDOR PÚBLICO. DESCONTO DOS DIAS NÃO TRABALHADOS EM VIRTUDE DE GREVE. JUSTIÇA DO TRABALHO.

1. Conquanto se reconheça que o Poder Constituinte Originário fez constar expressamente na Lei Maior o direito de os servidores aderirem a movimento grevista, até o presente momento o Poder Legislativo não cuidou de regulamentar o exercício do instituto pela categoria.

2. Instado a se manifestar acerca do procedimento a ser adotado ante a omissão legislativa, o STF, no julgamento dos Mandados de Injunções 
nํs 670/ES e 708/DF, firmou entendimento de que, enquanto não editada Lei Complementar pelo Poder Competente, aplicável seria a Lei n⿳o $7.783 / 1989$.

3. $\mathrm{O}$ artigo $7^{\circ}$ da Lei no $7.783 / 1989$ prevê de maneira expressa que a adesão dos trabalhadores à greve implica a suspensão do contrato de trabalho, o que, em regra, viabiliza a realização dos descontos nos salários dos servidores públicos nos dias efetivamente não laborados.

4. A deliberação administrativa do Tribunal Regional do Trabalho da 8a Região, no sentido da realização dos descontos dos dias não trabalhados pelos servidores, ante a adesão à greve no Poder Judiciário da União, encontra-se em consonância com a jurisprudência do STF e com a Resolução no 86 do CSJT, de observância obrigatória no âmbito da Justiça do Trabalho de primeiro e segundo graus.

\section{Recursos Administrativos em Pedidos de Providências conhecidos aos quais se nega provimento.}

Vistos, etc.

\section{Relatório}

Tratam-se de Recursos Administrativos interpostos nos Pedidos de Providências formulados por MARIA DO SOCORRO ABREU DE ARAÚJO ANTUNES, ALICE ROMANA DE JESUS PEREIRA, IDILBERTO NERY SILVA JUNIOR e MARIA DE BELÉM FERREIRA CAVALCANTE, todos servidores do Tribunal Regional do Trabalho da $8^{a}$ Região, em face de decisão monocrática proferida por este Relator que indeferiu os requerimentos.

A matéria em análise é efetivamente idêntica nos Pedidos de Providências $\mathrm{n} \mathrm{o}^{\mathrm{o}}$ 0000091-03.2012.2.00.0000, 0000187-18.2012.2.00.0000, 0000264-27.2012.2.00. 0000 e 0000270-34.2012.2.00.0000.

Nas peças vestibulares, os requerentes se insurgem contra o desconto, em seus vencimentos, de valores referentes aos dias não trabalhados, no período de 15-6-2011 a 26-7-2011, em decorrência de movimento grevista deflagrado pelo Sindicato que representa a categoria.

Afirmam que o TRT da 8a Região, por ordem verbal de seu Presidente ao Diretor de Recursos Humanos, proferiu decisão administrativa, expressa em Ata de Reunião do Comando de Greve, determinando o corte de ponto dos servidores correspondente ao período da greve, sem dar abertura para negociação. 
Prosseguem asseverando que a referida decisão administrativa é ilegal, uma vez que não permite a compensação dos dias paralisados pelos servidores, contrariando, assim, previsão contida no art. 44 da Lei 8.112/90 e posicionamento deste Conselho Nacional de Justiça.

Alegam ainda que o desconto causou sérios prejuízos ao sustento de suas famílias e que, por não ter sido dada a oportunidade de optar pela compensação, devem ser deferidos os pedidos de liminar e, ao final, afastada, em definitivo, a incidência da decisão administrativa do Tribunal requerido, possibilitando aos requerentes a compensação dos dias parados.

As medidas de urgência foram indeferidas.

Intimado a prestar informações, o TRT da 8ª Região suscitou questão preliminar de inadmissibilidade dos pedidos de providências, eis que a decisão ora impugnada, além de ser objeto de recurso administrativo, ainda pendente de julgamento, interposto pela entidade sindical representativa da categoria (processo TRT-8a/PL/RA/0001735-41.2011.5.08.0000), encontra-se judicializada nos autos do mandado de segurança no 001734-56.2011.5.08.0000, que tramita naquela Corte.

Ademais, informa que tramita no TRF da 1a Região a ação ordinária no 0048404-34.2011.4.01.000, também patrocinada pelo Sindicato, sob os mesmos pedidos e causa de pedir dos presentes autos.

Outrossim, alega ter ocorrido a perda parcial do objeto dos procedimentos em análise, tendo em vista a realização de audiência de conciliação nos autos do aludido mandado de segurança, na qual foi rejeitada, pela União, a proposta de compensação das horas não trabalhadas.

No mérito, sustenta ser inverídica a afirmação de que a Administração se recusou a negociar.

Assevera que o Sindicato somente pleiteou a reconsideração do ato após tomar conhecimento dos descontos, o que foi indeferido pelo Diretor de Secretaria de Pessoas, por despacho fundamentado.

Por fim, afirma que a prática do ato está amparada na autonomia constitucional da qual goza o Tribunal, na Resolução no 86 do Conselho Superior da Justiça do Trabalho e, ainda, na jurisprudência do STF.

Em razão da constatação da judicialização da matéria, foram proferidas decisões monocráticas que arquivaram os pedidos em tela, nos termos do inciso $\mathrm{X}$ do artigo 25.

Os recursos reiteram a argumentação inicial, ressaltando a independência entre as esferas administrativa e judicial, requerendo, ao final, a reforma da decisão monocrática proferida.

É, em síntese, o relatório. 


\section{Fundamentação}

Inicialmente, é importante frisar que este Conselho, por maioria, julgou improcedente o Pedido de Providências no 0005713-97.2011.2.00.0000, que versa sobre matéria idêntica à dos pedidos apresentados.

Naquela ocasião, o eminente Conselheiro Ministro Carlos Alberto foi designado relator para o acórdão, cujo teor segue transcrito abaixo:

A Constituição da República de 1988 assegura, no inciso VII do artigo 37, que o direito de greve dos servidores públicos será exercido nos termos e nos limites definidos em Lei específica.

Conquanto se reconheça que o Poder Constituinte Originário fez constar expressamente na Lei Maior o direito de os servidores aderirem a movimento grevista, tem-se que, até o presente momento, o Poder Legislativo não cuidou de regulamentar o exercício do instituto para a categoria, o que ensejou fosse instado o Supremo Tribunal Federal a se manifestar acerca do procedimento a ser adotado, ante a omissão legislativa.

O excelso STF, no julgamento dos Mandados de Injunção noㅗ $670 / E S$ e 708/DF, firmou que, enquanto não editada Lei Complementar pelo Poder Competente, aplicável seria a Lei no 7.783/1989.

Pacífico, portanto, o posicionamento de que a inexistência de norma específica não constitui óbice ao exercício do direito constitucional de greve para a categoria dos servidores públicos, devendo ser invocada, por analogia, a Lei que disciplina o instituto para os trabalhadores em geral e que regulamenta o artigo 9o da Carta Magna de 1988.

O artigo 7ํ da Lei no 7.783/1989 prevê de maneira expressa que a adesão dos trabalhadores à greve implica a suspensão do contrato de trabalho, o que, em regra, viabiliza a realização dos descontos nos salários dos servidores públicos nos dias efetivamente não laborados. Com efeito, tal qual assentado pelo STF, "nos termos do art. 7o da Lei no 7.783/1989, a deflagração da greve, em princípio, corresponde à suspensão do contrato de trabalho. Como regra geral, portanto, os salários dos dias de paralisação não deverão ser pagos, salvo no caso em que a greve tenha sido provocada justamente por atraso no pagamento aos servidores públicos civis, ou por outras situações excepcionais que justifiquem o afastamento da premissa da suspensão do contrato de trabalho (Art. 7º 
da Lei 7.783/1989, in fine)". (Mandado de Injunção nº 708/DF, Relator Ministro Gilmar Mendes).

Nesse mesmo sentido os seguintes precedentes do STF, verbis:

“Ementa: AGRAVOS REGIMENTAIS NO AGRAVO DE INSTRUMENTO. CONSTITUCIONAL E ADMINISTRATIVO. SERVIDOR PÚBLICO. DIREITO DE GREVE. MI 708/DF. DESCONTO REMUNERATÓRIO DOS DIAS DE PARALISAÇÃO. POSSIBILIDADE. PRECEDENTE. AGRAVO REGIMENTAL IMPROVIDO.

I - Inexiste direito à restituição dos valores descontados decorrentes dos dias de paralisação. Precedente. MI 708/DF, Rel. Min. Gilmar Mendes.

II - Não merece reparos a parte dispositiva da decisão agravada a qual isentou o Estado do Rio de Janeiro de restituir os descontos relativos ao período de paralisação.

III - Agravos regimentais improvidos." (Agravo Regimental em Agravo de Instrumento 824949/RJ, Relator Ministro Gilmar Mendes, 2a Turma do STF, publicado no DJE de 6 de setembro de 2011)

"Agravo regimental em agravo de instrumento. 2. Greve de servidor público. Descontos dos dias parados. Possibilidade. 3. Ausência de fundamentos suficientes para infirmar a decisão agravada. 4. Agravo regimental a que se nega provimento." (Agravo Regimental em Agravo de Instrumento, 2a Turma do STF, Relator Ministro Gilmar Mendes, publicado no DJE do STF de 20 de maio de 2011).

O próprio Conselho Superior da Justiça do Trabalho, órgão a que, nos termos do artigo 111-A, § 2o, inciso II, da Constituição da República de 1988, incumbe a uniformização de procedimentos no âmbito da Justiça do Trabalho de primeiro e segundo graus, seguindo diretriz traçada pelo Supremo Tribunal Federal e em consonância com a jurisprudência sedimentada na egrégia Seção Especializada em Dissídios Coletivos do TST, editou a Resolução no 86/2011, que dispõe, verbis:

“CONSELHO SUPERIOR DA JUSTIÇA DO TRABALHO

RESOLUÇÃO № 86, DE 25 DE NOVEMBRO DE 2011

Dispõe sobre os procedimentos administrativos a serem adotados em caso de paralisação do serviço por motivo de greve no âmbito do Conselho e da Justiça do Trabalho de primeiro e segundo graus.

O CONSELHO SUPERIOR DA JUSTIÇA DO TRABALHO, em sessão ordinária realizada em 25 de novembro de 2011, sob a presidência 
do Ex.mo Ministro Conselheiro João Oreste Dalazen (Presidente), presentes os Exmos. Ministros Conselheiros Maria Cristina Irigoyen Peduzzi, Renato de Lacerda Paiva, Emmanoel Pereira, os Exmos. Desembargadores Conselheiros Gilmar Cavalieri, Márcia Andrea Farias da Silva, José Maria Quadros de Alencar, Cláudia Cardoso de Souza, o Ex.mo Desembargador Francisco das Chagas Lima Filho, suplente do Ex.mo Desembargador Conselheiro Marcio Vasques Thibau de Almeida, a Ex.ma Subprocuradora-Geral do Trabalho, Maria Guiomar Sanches de Mendonça, e o Ex.mo Juiz Presidente da ANAMATRA, Renato Henry Santana;

Considerando a posição do Supremo Tribunal Federal nos autos da Reclamação no 6568/SP, de que se decidiu que o direito de greve dos servidores públicos não é absoluto, devendo sofrer relativização em decorrência da essencialidade de determinadas atividades públicas, dentre as quais se inclui a administração da Justiça;

Considerando as decisões do Supremo Tribunal Federal proferidas nos autos dos Mandados de Injunção nos 670-ES, 712-PA e 708- DF, no sentido da aplicabilidade da Lei no $7.783 / 89$ aos servidores públicos civis até a regulamentação da matéria por lei específica, nos termos do art. 37, VII, da Constituição da República;

Considerando a pacífica jurisprudência da Excelsa Corte, sedimentada nos Mandados de Injunção nos 670-ES e 708-DF e nos Agravos Regimentais em Agravos de Instrumento nos 824949/RJ e 795300/SP, no sentido de que a participação de servidores públicos em greve constitui, mutatis mutandis, causa de suspensão do contrato de trabalho, nos termos do art. 7ํ da Lei no $7.783 / 89$, circunstância que autoriza, em regra, o desconto da remuneração relativa aos dias não trabalhados;

Considerando que a Primeira Seção do Superior Tribunal de Justiça, nos autos do Mandado de Segurança no 15.272-DF e do Agravo Regimental na Petição no 8.050/RS, também pacificou o entendimento de que a paralisação de servidores públicos por motivo de greve implica o consequente desconto da remuneração relativa aos dias de falta ao trabalho, procedimento que pode ser levado a termo pela própria Administração, salvo acordo específico formulado entre as partes;

Considerando que a jurisprudência da Seção Especializada em Dissídios Coletivos do Tribunal Superior do Trabalho é igualmente firme no sentido de que, mesmo não tendo sido considerado abusivo o 
movimento paredista, salvo em situações excepcionais (entre elas, atraso no pagamento dos salários, lockout e/ou consenso das partes), a participação em greve suspende o contrato de trabalho e autoriza o desconto dos dias não trabalhados, conforme se extrai, entre outros, dos precedentes firmados nos processos RODC-87500-58.2006.5.15.0000, RODC-178000-10.2005.5.15.0000, DC-2173626-89.2009.5.00.0000, RODC-2018500-26.2008.5.02.0000， RODC-2036700-18.2007.5.02.0000, RODC- 20244/2005-000-02-00 e RO-6800-05.2008.5.23.0000;

Considerando que o inciso II do $\S 2$ o do art. 111-A da Constituição Federal atribui ao Conselho Superior da Justiça do Trabalho a competência para exercer a supervisão administrativa da Justiça do Trabalho de primeiro e segundo graus, como órgão central do sistema, cujas decisões terão efeito vinculante, cabendo-lhe, primordialmente, zelar pela regularidade do funcionamento das atividades essenciais dos tribunais trabalhistas;

Considerando que a administração da Justiça é serviço público essencial e indelegável prestado pelo Poder Judiciário, cuja conservação e regular funcionamento se impõem como medida de proteção e salvaguarda de outros direitos individuais e coletivos igualmente tutelados pela Constituição, e que atualmente se encontram ameaçados em virtude de paralisação parcial do serviço pela greve dos servidores públicos do Poder Judiciário da União;

Considerando, por fim, a necessidade de adotar-se um tratamento jurídico uniforme em todo o âmbito administrativo da Justiça do Trabalho de primeiro e segundo graus, em decorrência da deflagração de movimento grevista dos servidores públicos do Poder Judiciário da União;

\section{RESOLVE}

Art. 1ํㅡㄹ Esta Resolução estabelece os procedimentos administrativos a serem adotados no âmbito da Justiça do Trabalho de primeiro e segundo graus em caso de paralisação do serviço por motivo de greve.

Art. 2o O Presidente do Tribunal Regional do Trabalho, sob pena de responsabilidade, deverá descontar a remuneração dos servidores relativa aos dias de paralisação decorrentes de participação em movimento grevista, na folha de pagamento imediatamente subsequente à primeira ausência ao trabalho. 
Parágrafo único. As ausências de que trata este artigo não poderão ser objeto de:

I - abono;

II - cômputo de tempo de serviço ou qualquer vantagem que o tenha por base, exceto se compensadas, na forma estabelecida nesta Resolução.

Art. $3^{\circ}$ Cessada a adesão do servidor à greve, o valor do desconto na remuneração ainda não efetivado, a critério da Administração, poderá ser:

I - parcelado em até doze vezes;

II - compensado com eventual crédito líquido e certo já apurado em favor do servidor, e ainda não pago;

III - compensado mediante reposição das horas não trabalhadas, na forma prevista nesta Resolução.

Art. 4 A compensação de que trata o inciso III do artigo anterior darse-á mediante a efetiva prestação de serviço extraordinário, inclusive aos sábados, domingos, feriados e dias de recesso, desde que atendidos cumulativamente os seguintes requisitos:

I - real necessidade do serviço;

II - plano de trabalho específico; e

III - controle rigoroso e efetivo de cumprimento da jornada extraordinária.

Art. 5ㅇ O Presidente do Tribunal Regional do Trabalho, de ofício ou mediante solicitação das chefias das unidades administrativas e judiciárias, convocará servidores, em número suficiente, com o propósito de assegurar a continuidade das atividades essenciais.

Parágrafo único. Os servidores que, convocados, se recusarem a comparecer ao serviço não poderão ser beneficiados com a compensação de que trata o art. 4ํ da presente Resolução.

Art. 6o Esta Resolução entra em vigor na data de sua publicação

Brasília, 25 de novembro de 2011.

Ministro JOÃO ORESTE DALAZEN

Presidente do Conselho Superior da Justiça do Trabalho"

Conclui-se, assim, que a deliberação administrativa do Pleno do Tribunal Regional do Trabalho da 6a ${ }^{a}$ Região, no sentido da realização dos descontos dos dias não trabalhados pelos servidores, ante a adesão à 
greve no Poder Judiciário da União, encontra-se em consonância com a jurisprudência do STF e com a Resolução no 86 do CSJT, de observância obrigatória no âmbito da Justiça do Trabalho de primeiro e segundo graus.

Embora suficientes a fundamentar este voto, peço vênia para complementar as considerações feitas pelo ilustre Conselheiro Ministro Carlos Alberto naquele Pedido de Providências.

Antes da apreciação dos Mandados de Injunção nos 670/ES e 708/DF, o STF já sinalizava que, em havendo o Poder Público formalizado acordo para viabilizar a paralisação das atividades, estará reconhecendo a legitimidade das faltas dos servidores, mostrando-se insubsistente a suspensão do pagamento dos salários, tampouco a realização de descontos correspondentes aos dias parados, vejamos:

GREVE - SERVIDOR PÚBLICO - PAGAMENTO DA REMUNERAÇÃO. Se de um lado considera-se o inciso VII do artigo 37 da Constituição Federal como de eficácia limitada (Mandado de Injunção n⿳⺈ 20-4/DF, Pleno, Relator Ministro Celso de Mello, Diário da Justiça de 22 de novembro de 1996, Ementário no 1.851-01), de outro descabe ver transgressão ao aludido preceito constitucional, no que veio a ser concedida a segurança, para pagamento de vencimentos, em face de a própria Administração Pública haver autorizado a paralisação, uma vez tomadas medidas para a continuidade do serviço.

(RE 185944, Relator(a): Min. MARCO AURÉLIO, Segunda Turma, julgado em 17-4-1998, DJ 7-8-1998 PP-00042 EMENT VOL-01917-04 PP00790).

Acontece que a Administração Pública passou a se ver diante da ocorrência abusiva e desenfreada de movimentos paredistas no setor público brasileiro, com paralisações que chegam a se estender por meses.

A longa duração das greves provocou diversas discussões no meio jurídico acerca das soluções autocompositivas a serem adotadas pela Administração face aos dias de ausência, cada vez maiores, por parte dos servidores.

Em sua obra, o autor JOSÉ DOS SANTOS CARVALHO FILHO chama a atenção para tal acontecimento e relata que: 
(...) Várias greves de servidores, algumas com a duração de semanas e até de meses, não acarretaram qualquer efeito pecuniário ou funcional para os grevistas, parecendo mesmo que, em algumas oportunidades, o Governo teve que se curvar à força e às exigências do movimento. Foram noticiadas, inclusive, greves de magistrados, de policiais, de fiscais e de outras categorias em relação às quais o movimento grevista pareceria esdrúxulo e incompatível com as relevantes funções de seus agentes. ${ }^{1}$

A partir do julgamento dos Mandados de Injunção retro citados, o STF ponderou algumas possibilidades interpretativas quanto à aplicação analógica da Lei $\mathrm{n}^{\mathrm{0}} 7.783 / 89$ ao setor público, dentre as quais a faculdade da Administração de promover os descontos na folha de pagamento dos servidores grevistas, haja vista ter prevalecido o entendimento de que os dias de greve no serviço público caracterizam suspensão do contrato de trabalho, logo, não haveria de se falar em pagamento de salários, salvo se se tratar de matéria a ser decidida no julgamento do dissídio de greve, nesse caso, caberá ao Tribunal, apreciando a questão, entender pelo pagamento dos dias parados. $^{2}$

Com efeito, o Supremo Tribunal Federal assegurou à Administração a possibilidade de corte dos vencimentos dos servidores em greve.

O STJ também já concluiu pela possibilidade da medida, pois com a greve passa a vigorar uma "suspensão do contrato de trabalho", a seguir:

PROCESSUAL CIVIL E CONSTITUCIONAL - SÚMULA 266/STF - MANDADO DE SEGURANÇA - CORTE DO PONTO DE SERVIDORES GREVISTAS - MEDIDA QUE PODE SER LEVADA A TERMO PELA ADMINISTRAÇÃO.

1. O mandado de segurança não é sucedâneo de ação direta de inconstitucionalidade. Aplicação da Súmula 266/STF.

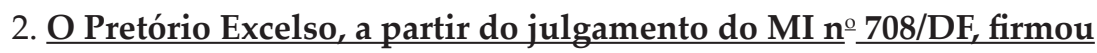
entendimento de que a paralisação de servidores públicos por motivo

\footnotetext{
${ }^{1}$ CARVAlHO FILHO, José dos Santos. Manual de direito administrativo. 24. ed. Rio de Janeiro: Lumen Juris, 2011. p. 695-696.

${ }^{2}$ FRAGA, Ricardo Carvalho; VARGAS, Luiz Alberto de. Greve dos servidores públicos e STF. Revista do Tribunal Superior do Trabalho, Brasília, v. 76, n. 2, p. 37, abr./jun. 2010. Porto Alegre: Magister Editora, 2010.
} 
de greve implica no consequente desconto da remuneração relativa aos dias de falta ao trabalho, procedimento que pode ser levado a termo pela própria Administração. Precedentes.

3. Segurança denegada.

(MS 15.272/DF, Rel. Ministra ELIANA CALMON, PRIMEIRA SEÇÃO, julgado em 29-9-2010, DJe 7-2-2011).

É importante salientar ainda, ressalvadas as devidas particularidades de cada fenômeno, que as consequências de uma greve no setor público não se mostram tão diferentes daquelas produzidas no âmbito privado, especialmente no tocante às atividades essenciais, não se justificando, portanto, um tratamento essencialmente distinto em situações análogas. ${ }^{3}$

Da mesma forma que o empregador pode efetuar descontos nos salários dos trabalhadores em razão de movimento grevista, a Administração também pode promover o corte dos vencimentos dos servidores que aderem à greve.

Além disso, vale ressaltar que a greve no serviço público implica grave lesão à ordem pública, sendo iminente o risco de transtornos de grande monta à ordem administrativa em geral, já que afeta a normal execução da prestação de serviços inadiáveis à comunidade.

Destarte, do mesmo modo que a paralisação dos servidores públicos acarreta prejuízo para toda a população, também gera implicações para os servidores participantes de movimento paredista, que devem estar preparados para arcar com o ônus dele decorrente.

Nesse sentido, observa-se a decisão do Ministro Gilmar Mendes abaixo:

DECISÃO: Trata-se de pedido de medida liminar em mandado de injunção, impetrado pela Federação Nacional dos Servidores do Poder Judiciário dos Estados e Distrito Federal e Outros, em razão de suposta omissão em editar lei complementar para regulamentar o exercício do direito previsto no art. 37, VII, da Constituição. Os impetrantes alegam, em síntese, que a demora na edição da lei prevista no referido dispositivo constitucional inviabiliza o exercício do direito de greve dos servidores do Poder Judiciário do Estado de São Paulo. Nesse sentido, asseveram que a decisão proferida por esta Corte nos Mandados de Injunção nos 708 e 712 - a qual determinou a aplicação analógica da Lei 7.783/1989

\footnotetext{
${ }^{3}$ Ibid., p. 39.
} 
para viabilizar o exercício de greve dos servidores públicos - não soluciona a questão em relação aos substituídos dos impetrantes, principalmente no que diz respeito ao desconto dos dias parados, à incompatibilidade entre a greve dos trabalhadores da iniciativa privada e a dos servidores, bem como aos critérios discricionários adotados na interpretação da Lei 7.783/1989 para amoldá-la ao caso prático. Tais medidas cerceariam o exercício do direito de greve. Por fim, pedem a concessão de medida liminar, a fim de suspender a Resolução 520/2010 do Tribunal de Justiça do Estado de São Paulo (TJ/SP), a qual determinou que fossem descontados os dias parados dos vencimentos dos servidores. Sustentam que a plausibilidade jurídica do pedido residiria na ausência de norma legal que autorize o desconto dos dias não trabalhados e no caráter alimentar impenhorável dos vencimentos. Por sua vez, a urgência da pretensão cautelar consistiria na necessidade de evitar dano patrimonial tanto aos servidores quanto ao TJ/SP. Passo a decidir tão somente o pedido de medida liminar. No presente mandado de injunção, os impetrantes postulam o reconhecimento do direito de greve dos servidores públicos civis (art. 37, VII, da Constituição Federal). Essa questão já foi objeto de apreciação desta Corte no julgamento dos MIs 670 (de minha relatoria, DJe 206, 30.10.2008), 708 (de minha relatoria, DJe 206, 30.10.2008) e 712 (Rel. Min. Eros Grau, DJe 23.11.2007). Na ocasião, determinou-se que, enquanto não editada a lei a que se refere o inciso VII do art. 37 da Constituição, deve ser aplicada aos servidores públicos a Lei 7.783/1989, no que couber. A decisão proferida, segundo a orientação desta Corte, possui eficácia erga omnes. A partir dessa determinação, verificou-se grande evolução na interpretação conferida pelo Supremo Tribunal Federal à conformação constitucional do mandado de injunção. Nesse quadro, admitiu-se que a decisão proferida em mandado de injunção pode configurar provimento de caráter aditivo. De outra sorte, a superação da orientação anterior desta Corte, no que diz respeito à natureza da decisão proferida, demanda também a revisão da jurisprudência quanto ao cabimento de medida liminar no mandado de injunção. Conforme salientei no julgamento dos MIs 670 e 708, da competência do Supremo Tribunal Federal para apreciar a omissão do legislador, inclusive proferindo decisões aditivas e com eficácia erga omnes, decorre, por exemplo, a faculdade de determinar a suspensão de processos administrativos ou judiciais, além de medidas ou atos administrativos, de modo a assegurar ao impetrante 
a possibilidade de ser beneficiado pela norma que vier a ser editada. Assim, admito o cabimento do pedido de medida liminar e passo a analisar a plausibilidade jurídica do pedido e a urgência da pretensão cautelar. Segundo os impetrantes, a plausibilidade jurídica do pedido residiria na ausência de norma legal que autorize o desconto dos dias parados e no caráter alimentar impenhorável dos vencimentos. Entretanto, em análise sumária da questão, verifico que, a princípio, a controvérsia dos autos se enquadra justamente na hipótese decidida por esta Corte, devendo ser aplicada aos substituídos do impetrante, no que couber, a Lei 7.783/1989, de modo a possibilitar-lhes o exercício do direito de greve. Nesse ponto, ressalto que a questão do desconto dos dias parados foi objeto de análise específica por parte desta Corte. Segundo a decisão proferida, nos termos do art. $7^{0} \underline{\text { da Lei }}$

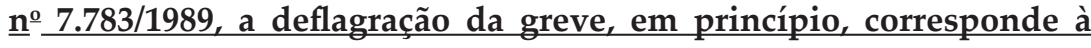
suspensão do contrato de trabalho. $\mathrm{E}$, havendo a suspensão, não há que se falar propriamente em prestação de serviços, tampouco no pagamento de salários. Como regra geral, portanto, os salários dos dias de paralisação não deverão ser pagos, salvo no caso em que a greve tenha sido provocada justamente por atraso no pagamento ou por outras situações excepcionais que justifiquem o afastamento da premissa da suspensão do contrato de trabalho. Por outro lado, não se diga que a natureza alimentar dos vencimentos impede a aplicação do artigo $7^{0}$ da Lei no $7.783 / 1989$. Caso contrário, estaria configurada hipótese de greve subvencionada pelo Poder Público. Ademais, a remuneração dos trabalhadores do setor privado também possui caráter alimentar e, em caso de greve, é plenamente aplicável o corte do ponto. Assim, não se justifica o tratamento diferenciado entre os servidores públicos e os trabalhadores do setor privado no que diz respeito ao desconto dos dias parados. Portanto, no caso ora em análise, salvo melhor juízo por ocasião do julgamento de mérito, não vislumbro a plausibilidade jurídica do pedido apta a ensejar a concessão da medida liminar pleiteada. Ante o exposto, indefiro o pedido de medida liminar. Requisitem-se as informações. Após, abrase vista dos autos à Procuradoria-Geral da República. Publique-se. Brasília, 26 de agosto de 2010. Ministro GILMAR MENDES Relator Documento assinado digitalmente.

(MI 3085 MC, Relator(a): Min. GILMAR MENDES, julgado em 26-82010, publicado em PROCESSO ELETRÔNICO DJe-162 DIVULG 31/08/2010 PUBLIC 1-9-2010) 
Ademais, frise-se que o desconto do salário, conforme decisões do STF, não configura "punição", mas mera consequência jurídica da "suspensão do contrato de trabalho", diferentemente das penalidades disciplinares dos servidores públicos, previstas no art. 127 da Lei 8.112/90, quais sejam: advertência, suspensão, demissão, cassação de aposentadoria ou disponibilidade, destituição de cargo em comissão, destituição de função comissionada, consoante decisão infratranscrita:

DECISÃO: Trata-se de agravo de instrumento interposto contra decisão de inadmissibilidade de recurso extraordinário que impugna acórdão assim ementado: “Administrativo. Servidor Público. Greve. 1. É legítimo o desconto dos dias da ausência ao posto do trabalho ou recusa ao exercício das atribuições do cargo, embora presente com assinatura do ponto, motivadas por greve. 2. O desconto salarial não se tipifica como punição disciplinar. Recurso improvido." (fl. 224) No recurso extraordinário, interposto com fundamento no art. 102, inciso III, alínea "a", da Constituição Federal, aponta-se violação ao art. 37, caput, da Carta Magna. A recorrente alega que "o desconto de seus vencimentos dos dias de paralisação conforme comprovados em seus holerites ora juntados, foi inconstitucional, por violentar o seu direito de greve, e ilegal, por não haver sido cumprido o artigo $7 \stackrel{0}{\text { da }}$ Lei 7.783/89". (fl. 269) Decido. O Plenário desta Corte, no julgamento do Mandado de Injunção n. 708, de minha relatoria, DJe 31.10.2008, reconheceu o direito de greve dos servidores públicos civis e determinou a aplicação, à hipótese, das Leis 7.701/88 e 7.783/89, inclusive quanto ao art. ํ da Lei 7.783/89, correspondente à suspensão do contrato de trabalho neste período e o respectivo desconto dos dias de paralisação. Nesse sentido, confira-se: “MANDADO DE INJUNÇÃO. GARANTIA FUNDAMENTAL (CF, ART. 5을 INCISO LXXI). DIREITO DE GREVE DOS SERVIDORES PÚBLICOS CIVIS (CF, ART. 37, INCISO VII). EVOLUÇÃO DO TEMA NA JURISPRUDÊNCIA DO SUPREMO TRIBUNAL FEDERAL (STF). DEFINIÇÃO DOS PARÂMETROS DE COMPETÊNCIA CONSTITUCIONAL PARA APRECIAÇÃO NO ÂMBITO DA JUSTIÇA FEDERAL E DA JUSTIÇA ESTADUAL ATÉ A EDIÇÃO DA LEGISLAÇÃO ESPECÍFICA PERTINENTE, NOS TERMOS DO ART. 37, VII, DA CF. EM OBSERVÂNCIA AOS DITAMES DA SEGURANÇA JURÍDICA E À EVOLUÇÃO JURISPRUDENCIAL NA INTERPRETAÇÃO DA OMISSÃO LEGISLATIVA SOBRE O 
DIREITO DE GREVE DOS SERVIDORES PÚBLICOS CIVIS, FIXAÇÃO DO PRAZO DE 60 (SESSENTA) DIAS PARA QUE O CONGRESSO NACIONAL LEGISLE SOBRE A MATÉRIA. MANDADO DE INJUNÇÃO DEFERIDO PARA DETERMINAR A APLICAÇÃO DAS LEIS №s 7.701/1988 E 7.783/1989. 1. SINAIS DE EVOLUÇÃO DA GARANTIA FUNDAMENTAL DO MANDADO DE INJUNÇÃO NA JURISPRUDÊNCIA DO SUPREMO TRIBUNAL FEDERAL (STF). (...) 6.4. Considerados os parâmetros acima delineados, a par da competência para o dissídio de greve em si, no qual se discuta a abusividade, ou não, da greve, os referidos tribunais, nos âmbitos de sua jurisdição, serão competentes para decidir acerca do mérito do pagamento, ou não, dos dias de paralisação em consonância com a excepcionalidade de que esse juízo se reveste. Nesse contexto, nos termos do art. 7ํ da Lei no 7.783/1989, a deflagração da greve, em princípio, corresponde à suspensão do contrato de trabalho. Como regra geral, portanto, os salários dos dias de paralisação não deverão ser pagos, salvo no caso em que a greve tenha sido provocada justamente por atraso no pagamento aos servidores públicos civis, ou por outras situações excepcionais que justifiquem o afastamento da premissa da suspensão do contrato de trabalho (art. 7을 da Lei no 7.783/1989, in fine). (...) 6.7. Mandado de injunção conhecido e, no mérito, deferido para, nos termos acima especificados, determinar a aplicação das Leis $n^{\underline{o s}}$ 7.701/1988 e 7.783/1989 aos conflitos e às ações judiciais que envolvam a interpretação do direito de greve dos servidores públicos civis". (grifei) No mesmo sentido, cito as seguintes decisões monocráticas: RE 579.012, Rel. Min. Cármen Lúcia, DJe 29.11.2010; RE 564.762, Rel. Min. Cármen Lúcia, DJe 21.10.2010; RE 478.936, Rel. Min. Dias Toffoli, DJe 12.11.2010; RE 456.530, Rel. Min. Joaquim Barbosa, DJe 31.5.2010; RE 476.314, Rel. Min. Joaquim Barbosa, DJe 7.6.2010; RE 539.042, Rel. Min. Ricardo Lewandowski, DJe 18.2.2010. Nesses termos, são legítimos os descontos realizados nos vencimentos dos servidores relativamente aos dias não trabalhados. Ante o exposto, nego seguimento ao recurso (arts. 21, § 1o do RISTF, e 557 do CPC). Publique-se. Brasília, 2 de março de 2011. Ministro GILMAR MENDES Relator Documento assinado digitalmente.

(AI 795300, Relator(a): Min. GILMAR MENDES, julgado em 2-3-2011, publicado em DJe-050 DIVULG 16-3-2011 PUBLIC 17-3-2011) 
É legítimo, portanto, à Administração Pública proceder ao desconto remuneratório dos dias parados, ressalvada a adoção de medidas autocompositivas em benefício dos servidores participantes do movimento, conforme assinala a parte final do dispositivo da Lei 7.783/89 - art. 7‥ Isto quer dizer, não havendo ânimo, por parte de qualquer um dos interessados, inclusive da Administração, de fazer a compensação, pode esta, desde logo, optar pelo desconto.

Nessa linha, confira-se o seguinte precedente:

EMENTA: EMBARGOS DECLARATÓRIOS CONVERTIDOS EM AGRAVO REGIMENTAL. GREVE DE SERVIDOR PÚBLICO. DESCONTO PELOS DIAS NÃO TRABALHADOS. LEGITIMIDADE. JUNTADA POSTERIOR DE TERMO DE COMPENSAÇÃO DE JORNADA. EXAME INVIÁVEL. ENUNCIADO 279 DA SÚMULA DO STF. DESPESAS PROCESSUAIS. SUCUMBÊNCIA INTEGRAL. HONORÁRIOS ADVOCATÍCIOS. APRECIAÇÃO EQUITATIVA. ART. 20, $\S 4$ ㅇ, CPC. A comutatividade inerente à relação laboral entre servidor e Administração Pública justifica o emprego, com os devidos temperamentos, da ratio subjacente ao art. $7^{\circ}$ da Lei $7.783 / 89$, segundo o qual, em regra, "a participação em greve suspende o contrato de trabalho". Não se proíbe, todavia, a adoção de soluções autocompositivas em benefício dos servidores-grevistas, como explicitam a parte final do artigo parcialmente transcrito e a decisão proferida pelo STF no MI 708 (item 6.4 da ementa). Todavia, revela-se inviável, nesta quadra processual, o exame de "termo de compromisso" somente agora juntado, consoante o verbete 279 da Súmula. Agravo regimental a que se dá parcial provimento somente para esclarecer os ônus da sucumbência.

(RE 456530 ED, Relator(a): Min. JOAQUIM BARBOSA, Segunda Turma, julgado em 23-11-2010, DJe-020 DIVULG 31-1-2011 PUBLIC 1-2-2011 EMENT VOL-02454-04 PP-00972).

Novamente, os dias correspondentes à paralisação podem ser descontados dos vencimentos dos servidores paredistas. Todavia, é importante frisar que a Administração possui a faculdade de adotar outro mecanismo recompositivo como, por exemplo, a extensão dos expedientes dos servidores para recuperação das horas de trabalho que a greve consumiu. 
O Tribunal pode, então, optar pela compensação das horas não laboradas ou qualquer outra forma de composição, sendo válidos, igualmente, os descontos sobre vencimento de servidores públicos, intentado pelo Poder Público na ocorrência de movimento paredista, eis que ao direito de greve por parte do prestador do serviço - servidor público -, corresponde o direito de suspensão do pagamento pelo empregador - Administração Pública.

\section{Conclusão}

Por todo o exposto, conheço dos Recursos Administrativos para negarlhes provimento.

\section{Conselheiro GILBERTO VALENTE MARTINS}

Relator 